\title{
Las mujeres indígenas amazónicas: Actoras emergentes en las relaciones Estado - organizaciones indígenas amazónicas, durante el gobierno de Alianza País en el Ecuador
}

\author{
Ivette Rossana Vallejo Real \\ FLACSO, Quito, Ecuador \\ Email: ivallejo@flacso.edu.ec \\ Corinne Duhalde Ruiz \\ Investigadora independiente, Quito, Ecuador \\ Email: corineduhalde@hotmail.com
}

\begin{abstract}
Resumen: En diálogo con estudios sobre etnicidad, política indígena y género en América Latina, el artículo analiza las complejas relaciones entre el Estado y organizaciones indígenas amazónicas en el Ecuador y profundiza en la politización de las mujeres en el contexto de la profundización del extractivismo petrolero y el impulso de la minería a gran escala en el decenio 2007 - 2017 durante el gobierno de Alianza País, alineado al Socialismo del Siglo XXI. Si bien las organizaciones indígenas otorgaron respaldo inicial al gobierno, por su acogida a demandas como el reconocimiento de la plurinacionalidad y la interculturalidad, desde el 2013 divergieron entre posiciones de defensa de los territorios indígenas, y en otros casos de alianza con la política gubernamental. En medio de la fragmentación y debilitamiento organizativo, mujeres lideresas de pueblos kichwa, shuar, shiwiar, sapara y waorani encontraron oportunidades para sostener la resistencia, contestar a las promesas estatales de desarrollo y Buen Vivir, a la par que posicionaron específicas demandas de género.
\end{abstract}

Palabras clave: agencia política, resistencia, mujeres indígenas, neo-extractivismo, Amazonía.

\section{Amazonian indigenous women: Emerging actors in state relations - Amazonian indigenous organizations, during the Alianza País government in Ecuador}

\begin{abstract}
In a dialogue with studies on ethnicity, indigenous politics and gender in Latin America, the article analyzes the complex relations between the State and Amazonian indigenous organizations in Ecuador and deepens in the politicization of women in the context of the deepening of oil extractivism and the impulse of large scale mining on the decade 2007 - 2017 during the government of Alianza País, aligned to the Socialism of the XXI Century. Although indigenous organizations granted initial support to the government, due to their acceptance of demands such as the recognition of plurinationality and interculturality, since 2013 they have diverged between positions of defense of indigenous territories, and in other cases of alliance with government policy. In the midst of organizational fragmentation and weakening, women leaders from the Kichwa, Shuar, Shiwiar, Sapara and Waorani peoples found opportunities to sustain resistance, respond to the state promises of development and Good Living, while at the same time positioning specific gender demands.
\end{abstract}

Keywords: political agency, resistance, indigenous women, neo-extractivism, Amazon. 


\section{Mulheres indígenas da Amazônia: atores emergentes nas relações com o Estado - organizações indígenas da Amazônia, durante o governo da Alianza País no Equador}

Resumo: Em diálogo comestudos sobre etnicidade, política indígena e gênerona América Latina, o artigo analisa as complexas relações entre as organizações indígenas e o Estado naAmazônia no Equador e investiga a politização das mulheres no contexto do aprofundamento da extractivismo do petróleo e o impulso da mineração em grande escala na década de 2007 - 2017 durante o governo de Alianza País, alinhado ao socialismo do século XXI. Enquanto organizações indígenas deramapoio inicial para o governo, por suabem-vindo para demandas como o reconhecimento da diversidade nacional e multiculturalismo, a partir de 2013 eles divergiram entre as posiçõesem defesa dos territórios indígenas, e emoutros casos emaliançacom a política do governo. Emmeio a fragmentação e fragilidade organizacional, mulheres dos povosKichwa, Shuar, Shiwiar, Sapara e Waorani encontraron oportunidades para sustentar a resistência, responder as promessas de Estado de Desenvolvimento e BomViver, aomesmo tempo posicionaron demandas específicas de gênero.

Palavras-chave:Agênciapolítica, resistência,mulheresindígenas, neoextrativismo, Amazônia

\section{Introducción}

Este artícelo aborda la participación y el lugar social de las mujeres indígenas de la Amazonía en las políticas étnicas de las organizaciones indígenas en el Ecuador. En un contexto de profundización extractiva acaecida durante la década del 2007 al 2017 durante el gobierno de Alianza País, que se posicionó dentro de un conjunto de gobiernos alineados hacia la izquierda y el socialismo de nuevo siglo (XXI), el artículo intenta responder a las siguientes preguntas: ¿en medio de las variadas formas de posicionamiento que adoptaron las organizaciones indígenas en la Amazonía ecuatoriana (entre alianza y contestación), a lo largo del decenio, qué lenguajes de movilización y repertorios de acción configuraron las mujeres indígenas?, ¿ ¿cuál es el alcance de la politización de las mujeres indígenas y de sus planteamientos ante el Estado?, y ¿qué repercusiones ha tenido su politización en las estructuras organizativas indígenas?

En congruencia con las teorías post estructurales de la ecología política consideramos que el poder media las relaciones humano-ambientales, y sin prescindir del andamiaje de los constreñimientos impuestos por modelos de desarrollo relacionados con el sistema-mundo capitalista, adoptamos el interés por las agencialidades que se despliegan en las interacciones entre lo local, regional y global (Biersack, 2006). En diálogo con la ecología política feminista por su parte, consideramos que el género es una construcción social que condiciona el acceso y el control diferencial de hombres y mujeres a recursos naturales, más aún cuando se dan intersecciones con otras estructuras de la desigualdad (clase, etnicidad, y localización geográfica). Ponemos énfasis en los "procesos de toma de decisiones y el contexto económico, político y social que conforma las políticas y las prácticas ambientales” (Rocheleau, et al, 1996: 345), y en cómo las mujeres se configuran como sujetos políticos en las contiendas ambientales, como las que abordamos en el artículo derivadas de la profundización extractiva en la Amazonía ecuatoriana. Varias categorías como etnicidad, política étnica, repertorios de acción, agencia, las tomamos de varios campos disciplinares, desde la Antropología Política, pasando por la teoría de la acción social (más sociológica), a la Ecología Política.

El artículo deviene de reflexiones de varios años de investigación en la Amazonía, principalmente en la Amazonía centro a partir de un proyecto de investigación sobre ecologías políticas de la diferencia en lugares del circuito petrolero I y II efectuado desde FLACSO Ecuador (2014-2016) y seguimientos posteriores (hasta la fecha) a los procesos organizativos y políticos de mujeres indígenas frente al extractivismo. En la investigación se efectuó observación participante de eventos organizativos y repertorios de acción de las mujeres amazónicas (marchas, emplazamientos en Puyo y Quito), entrevistas a profundidad con mujeres lideresas amazónicas de la provincia de Pastaza y dirigentes de Amazonía norte y centro, cartografía social, revisión documental y talleres (más específicamente con técnicos, técnicas, y lideresas kichwa de Pastaza).

El texto comienza con una mirada retrospectiva a la agencia política amazónica en el Ecuador, prosigue con una descripción analítica sobre las relaciones entre organizaciones y Estado durante el gobierno de Alianza País, para después discutir si las mujeres amazónicas, son actoras emergentes. El argumento que se teje a lo 
largo del artículo sostiene que si bien a lo largo del decenio 2007-2017 las mujeres amazónicas se tornaron más visibles al presentarse con vocería propia, articulándose sin desligarse de sus organizaciones mixtas para aunar voces frente a la profundización extractiva que amenaza con despojo en sus territorios y afectación de medios de vida, las mujeres consideran que no es de ahora, sino desde décadas atrás que han ido hilando su participación desde sus bases territoriales. En medio de la fragmentación y debilidad del movimiento indígena encontraron oportunidades para posicionar sus demandas de género a la par que sostuvieron la resistencia. El alcance de su agencia radica en que de no haberse movilizado y logrado legitimarse como actoras públicas, la explotación petrolera se hubiera impuesto en Pastaza, en la Amazonía centro. Su protagonismo y participación, se ancla en las redes nacionales y globales de las que forman parte, en contiendas que trascienden al ámbito del Estado.

\section{Mirada retrospectiva a la agencia política amazónica en el Ecuador}

En la Amazonía la agencia política indígena está siempre en una continua conformación, no obstante es importante diferenciar entre las formas de ejercicio de poder tradicional ${ }^{1}$ y aquellas que los pueblos indígenas han implementado con el fin de "adaptar, negociar y enfrentar su relación con las sociedades estatalizadas" (Correa F et al., 2017,p.21). En esta segunda forma pueden situarse las dirigencias indígenas muchas veces bajo el control del Estado (Gros, 1999 en Chaumeil, 2017). Antiguos líderes indígenas pasan a participar en calidad de funcionarios del sector público o al servicio de grandes proyectos dentro de las industrias (petrolera y minera), o como empleados en las agencias del Estado; dándose un proceso de burocratización. A veces se adopta una facultad mimética como medio de apropiación del poder del otro, como medio o instrumento de negociación.

A un nivel macro, el proceso de politización étnica se desenvuelve "en un contexto de globalización con profundo impacto sobre las sociedades indígenas, cuyas visiones de mundo se ven coladas ante una fusión de intereses e imaginarios transnacionales (...) ideopanoramas o sistemas ideacionales (...) que son apropiados y resignificados por las organizaciones y líderes indígenas en su accionar como agentes de intermediación entre horizontes culturales” ante una gama de actores. (Vallejo 2003, p. 188)

El proceso organizativo indígena en la Amazonía ecuatoriana se fue fraguando entre las décadas del 60 al 70 por la urgencia de legalizar tierras para frenar los flujos de colonización propiciados por las políticas de reforma agraria y colonización del Instituto Ecuatoriano de Reforma Agraria (IERAC). Desde las organizaciones posteriormente las agendas estuvieron relacionadas con el fortalecimiento cultural, la educación bilingüe, y proyectos de auto-sustentación (Vallejo 2003). Entre las décadas de los 80, 90 y 2000 la demanda de derechos territoriales y la titulación fueron centrales. Esto significó pensarse como pueblos y nacionalidades, crear visiones de soberanía en sincronía con el reconocimiento de derechos a nivel internacional con cuestiones como la autodeterminación y reconocimiento cultural (Yashar, 2005; Postero y Zamosc, 2004). Las organizaciones fueron cambiando sus formas de nombrarse, así pasaron de Asociaciones que conforman Federaciones a autodenominarse Nacionalidades, ${ }^{2}$ en una coyuntura en que el extractivismo petrolero, la extracción forestal, la construcción de ejes viales y procesos de urbanización moldeaban la Amazonía.

En los procesos organizativos indígenas amazónicos y su etnopolítica la influencia y alianzas con agentes externos como ONG han sido importantes para la formación de liderazgos, en fortalecer los procesos en la articulación de comunidades y asociaciones, también en la conformación de nexos y redes pan indígenas regionales, nacionales e internacionales (Martínez Novo, 2006; Brysk, 2000; Rappaport, 2005). Reconocer estas influencias y tejidos de alianza no significa ubicar a los pueblos indígenas como sujetos pasivos, sino evitar mistificarlos (Martínez Novo, 2013). En general, las organizaciones indígenas se fueron configurando en medio del neoliberalismo, que estimuló la descentralización y la participación social reduciendo la intervención del Estado (Brysk, 2000; Postero, 2007, en Martínez Novo, 2013).

Hacia el nuevo milenio se produjo una ecologización de las demandas étnicas en la Amazonía (Martínez Sastre, 2011) y se enlaza la etnicidad con la cuestión ambiental, que se apropió en enlace con las ONG ecologistas. Las representaciones de resistencia asumieron la defensa de territorios con bosques tropicales, como estrategia para su reproducción social, y como un medio para formular reivindicaciones identitarias, políticas y territoria- 
les, a fin de resistir al colonialismo ecológico y a la ecogubernamentalidad (Ulloa, 2001). Los procesos organizativos indígenas por tanto articularon definiciones de derechos en medio de las políticas hegemónicas de la ecocracia y el multiculturalismo neoliberal (Martínez Sastre, 2011).

\section{Entre alianzas y resistencias en el Socialismo del Siglo XXI}

En el decenio 2007-2017, durante el gobierno del movimiento Alianza País, presidido por Rafael Correa había una correlación de fuerzas en América Latina, con una agenda de integración en el marco del denominado Socialismo del Siglo XXI. Con el slogan de "la patria vuelve” y "la patria ya es de todos”, se ofreció respuestas a la crisis económica, y al debilitamiento del Estado acarreados por gobiernos neoliberales previos (Lu et al., 2017).

Inicialmente el movimiento indígena articulado a la Confederación de Nacionalidades Indígenas del Ecuador (CONAIE) con sus filiales como la Confederación de Nacionalidades Indígenas de la Amazonía Ecuatoriana (CONFENIAE) brindaron apoyo al gobierno (Van Cott, 2009), al converger en cuestionamientos al neoliberalismo y a acuerdos de libre comercio (Becker, 2013). En el contexto de la Constituyente en el 2008, hubo expectativa al adoptarse el carácter Plurinacional del Estado, derechos colectivos de pueblos indígenas, montubios y afrodescendientes (Art 57), el reconocimiento de la Pachamama (naturaleza) como sujeto de derechos, y el SumakKawsay (traducido como Buen Vivir) en la Constitución. Tanto las organizaciones ecologistas, como el movimiento indígena consideraban que se abría paso a un modelo post neoliberal y post extractivo al asumir principios que conlleven a una armonización entre sociedad y naturaleza.

En el entendimiento entre Estado y organizaciones indígenas hubo sucesos como el Mandato minero de 2008, que posibilitó se revisen concesiones mineras en el país; la renegociación de los contratos petroleros con un mayor margen de ganancias para el Estado (Escribano, 2013; Ruiz 2013 en Bayón y Wilson, 2017) y la Iniciativa Yasuní ITT, que consistía en mantener el crudo bajo tierra en los campos Ishpingo, Tambococha y Tiputini en el Parque Nacional Yasuní, con colaboración financiera internacional para mitigar el cambio climático.

En el 2010 la CONAIE retiró su apoyo al gobierno nacional al sentirse marginalizados del proyecto político de Correa (Becker, 2013) y al percibir su tendencia autoritaria. Aspectos detonadores fueron la revocación de la autonomía de las organizaciones indígenas para manejar el sistema de educación intercultural bilingüe, las nuevas leyes de minería y de agua formuladas sin la participación indígena (Martínez Novo, 2011), y la muerte de Bosco Wisum, profesor indígena en el 2009 tras manifestaciones y la represalia gubernamental a las expresiones en contra de la minería y en defensa del agua en la Amazonía sur (Becker, 2013; Rénique, 2009).

En adelante ocurriría la desmovilización de los movimientos populares (Becker, 2013) y la judicialización de la resistencia.

En el 2013 el gobierno cesó la Iniciativa Yasuní ITT, dio paso a la explotación de los bloques 31 y 43 en el Yasuní, y previo a ello, el 28 de noviembre de 2012, 13 bloques fueron puestos en licitación -en el marco de la convocatoria a la XI Ronda petrolera- en las provincias de Napo, Pastaza y Morona Santiago. Estos se traslapaban en un $100 \%$ sobre territorios achuar, andoa, shiwiar y sapara; un $70 \%$ sobre territorio shuar y en un 16,34\% del territorio waorani (Mazabanda, 2013). Los bloques 79 y 83 se concesionaron a la empresa China Andes Petroleum por sobre comunidades sapara, kichwa y shiwiar e incluso pueblos indígenas aislados en el Yasuní en el caso del bloque 83. Así mismo, el bloque 29 fue concesionado a la subsidiaria de Cuba de la española Repsol; y el bloque 28 a la estatal ecuatoriana PetroAmazonas en consorcio con ENAP de Chile y Belorusneft de Bieolorusia (Vallejo 2014). Adicionalmente se amplió el bloque 10 operado por AGIP, por más de 20 años en la zona de Villano. Otras dinámicas de intensificación también se vivenciaron en la Amazonía norte con una larga data de actividades petroleras desde la década del primer auge en los 60. Ocurrieron recambios en los contratos petroleros y una mayor presencia de la empresa estatal PetroAmazonas en la operación de varios bloques.

En la Amazonía sur, tres proyectos de megaminería fueron impulsados en la Cordillera del Cóndor en las provincias de Morona Santiago y Zamora Chinchipe afectando una zona altamente biodiversa, en que habi- 
tan comunidades shuar y comunidades campesinas mestiza y de ascendencia indígena, que provenientes del Azuay colonizaron la zona en décadas previas. Se vigorizó el sector minero a gran escala (a cielo abierto) a fines de 2008. Para ello configuró un marco normativo propicio para atraer la inversión minera ${ }^{3}$.

En el 2012 con la firma del proyecto Mirador entre el Ministerio de Recursos No Renovables, el presidente de la República y el representante de la compañía minera Ecuacorriente SA (ECSA) operado por el consorcio chino Tongling CRCC se inauguró la minería a gran escala en el país (Riofrío, 2017, p.47). Tras este, siguió en 2016 la firma del contrato de inversión con Lundingold (empresa canadiense) para la explotación del proyecto Fruta del Norte, mientras en Morona el proyecto San Carlos Panantza está en fase de explotación avanzada.

Varias narrativas legitimadoras acompañaron los ofrecimientos de inversión social en zonas de directa influenciadas de proyectos estratégicos del Estado, con el $12 \%$ de la renta petrolera y 60\% de regalías mineras destinadas a proyectos productivos y de desarrollo local sustentable a través de municipios y juntas parroquiales. Las estrategias discursivas propias del neo-extractivismo mostraron al petróleo y minería como conducentes al Buen Vivir; productores de una Nueva Amazonía. Varias frases como "el petróleo te conecta, mejora tu comunidad” (Vallejo y Duhalde, 2016, p. 231), y “Minería para el buen Vivir” crearon espejismos, implantaron una modernidad barroca y fantasías utópicas (Bayón y Wilson, 2017).

Se efectuaron inversiones en el corredor interocéanico Manta-Manaos, ciudades del milenio (Pañacocha y Playas de Cuyabeno en el bloque 12; Dureno en bloque 75), en la construcción de Unidades Educativas del Milenio, parques lineales como en Sacha, que ocultaron el creciente despojo de territorios y la afectación ecológica. Se hizo énfasis en la construcción de una Nueva Amazonía libre de marginalidad y pobreza con poblaciones indígenas integradas plenamente al Estado nacional y la economía global.

Si en el período del neoliberalismo hubo pautas multiculturales de reconocimiento cultural a expensas de agendas de clase (Breton, 2008; Almeida, 2005), que dejaron intactas las estructuras socioeconómicas que reproducen la explotación económica y la desposesión de indígenas (Becker, 2013); en el gobierno del decenio de Alianza País (de pretendido post neoliberalismo), el discurso de inclusión, de superación de la pobreza utilizó en cambio un andamiaje basado en la estructura de clases. Se enunció que se apuntalaría un cambio de matriz productiva, y que un nuevo modo de acumulación basado en una economía diversificada y sustentable, con tecnología de punta "reemplazaría a un capitalismo socialmente excluyente y ecológicamente catastrófico basado en la explotación de reservas petroleras de la Amazonía” (Bayón y Wilson, 2017,p.19).

El gobierno de Correa y la relación con las organizaciones de los pueblos y nacionalidades indígenas se tensionó a lo largo del decenio, en el encuadre del consenso de los commodities (2000-2010) que reorientó la economía regional aumentando la dependencia fiscal de materias primas y su peso en la canasta de exportación (Ruiz Acosta e Iturralde, 2013). Un actor predominante en ello fue China, primer exportador de bienes en el mundo, consumidor de energía, de aluminio, cobre, estaño, zinc, soya; segundo consumidor de petróleo (Sevares, 2011 en Chicaiza, 2014), con altos requerimientos de recursos para sostener su economía.

En cuanto a la mega minería, se materializó la apropiación del espacio y alteraron territorialidades existentes (Warnaars et al., 2017). La compra de tierras bajo presión y engaño y en lo posterior desde el 2015 la figura de servidumbre fueron emprendidas para legitimar la expropiación de tierras de campesinos colonos que no acordaban vender sus fincas a las empresas, utilizándose de forma desmedida la fuerza, generando intimidación y miedo ${ }^{4}$. El Estado a través de la Agencia Reguladora de Minería (ARCOM), la Secretaría Nacional del Agua (SENAGUA) y el Ministerio del Interior actuaron facilitando la expansión territorial de los proyectos mineros (Teijlingen et al., 2017) y la fuerza pública (policía y militares) coordinaron con empresas de seguridad privada para asegurar los despojos e implantar una "vigilancia permanente de la circulación de personas en su propio territorio” (Sacher et al., 2016, p. 5).

En la Amazonía centro en el marco de la XI Ronda, el gobierno propició distanciamiento entre dirigencias y bases, reclutó líderes indígenas como funcionarios de instituciones del Estado, y conformó organizaciones paralelas (Zamosc, 2007 en Martínez Novo, 2013, p. 483), perfeccionado las estrategias similares de gobiernos 
neoliberales. Se cooptó a dirigentes kichwa referentes de procesos de lucha por el territorio y la autonomía, e intentó fragmentar a las nacionalidades Achuar (NAE) y Shiwiar (NASHIE) (Vallejo et al. 2017), que en décadas previas conformaron un Comité Interfederacional ante otras rondas de licitación y que ante la XI Ronda no permitieron la entrada de funcionarios para procesos de Consulta Previa, al considerar que el Decreto 1247 que los facultaba, no garantizaba derechos. Hubo varios momentos en el 2015 en que NAE y NASHIE tuvieron quiebres internos, dirigencias depuestas, entre otros problemas ${ }^{5}$.

Figura 1.

Banner de oposición a la XI Ronda en sede de Nacionalidad Achuar (NAE)

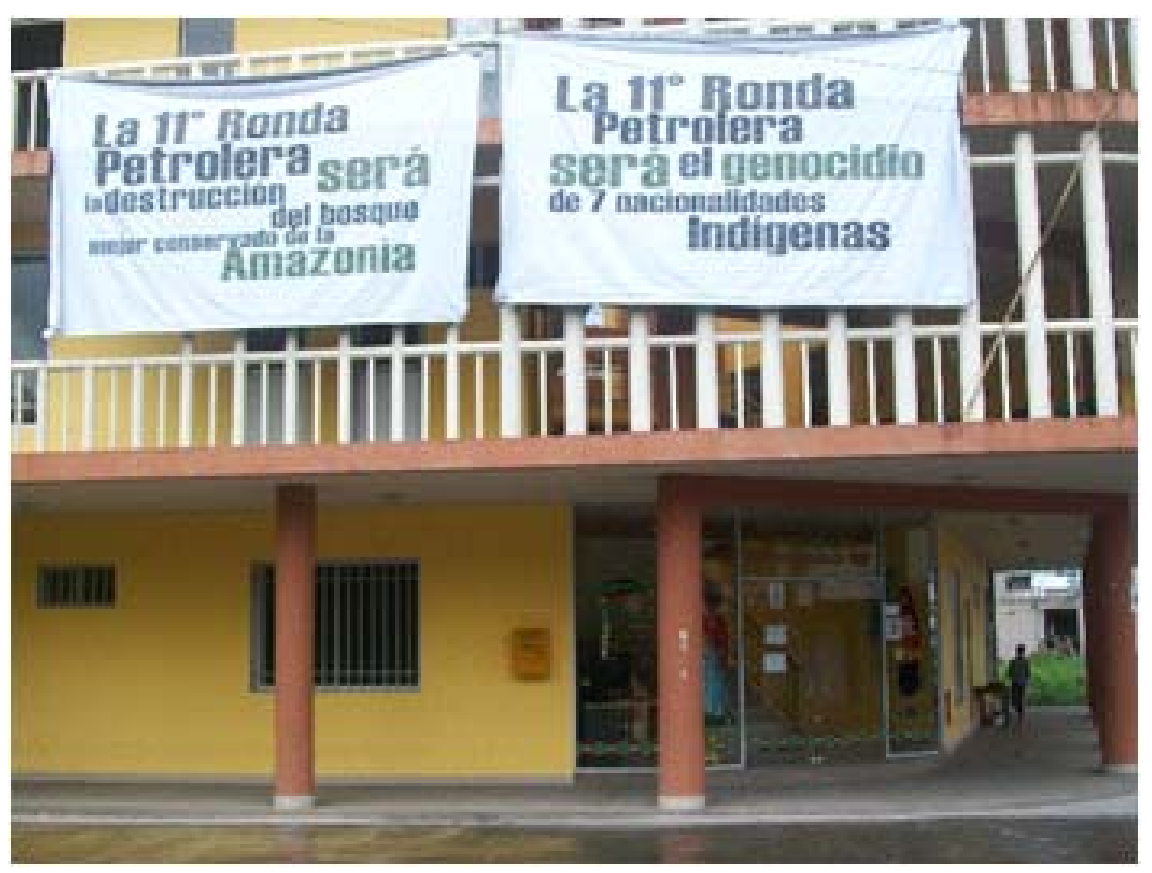

Fotografía de Ivette Vallejo

Desde entidades del gobierno se intentó socavar el tejido social indígena, y en territorios como el Sapara se creó un clima de confrontación fuerte entre comunidades y facciones dirigenciales, con un historial de dinámicas de disputa por la representación política de la nacionalidad sapara. Una dirigencia asentada en la sede en el poblado de Shell, apoyaba la política extractiva en aras de acceder a ofrecimientos de desarrollo, mientras que en la Asociación de Mujeres Ashiñwaka el posicionamiento de lideresas como Gloria Ushiwa contestaba al extractivismo en salvaguarda de la integridad del territorio, identidad y cultura, lo que les expuso a ellas y a sus comunidades, a la intimidación por parte de dirigentes afines al Estado (Farías, 2018). 
Figuras 2 y 3.

Pancarta en sede de NASE en Shell y otra en sede de la Asociación de Mujeres Sapara Ashiñwaka en Puyo
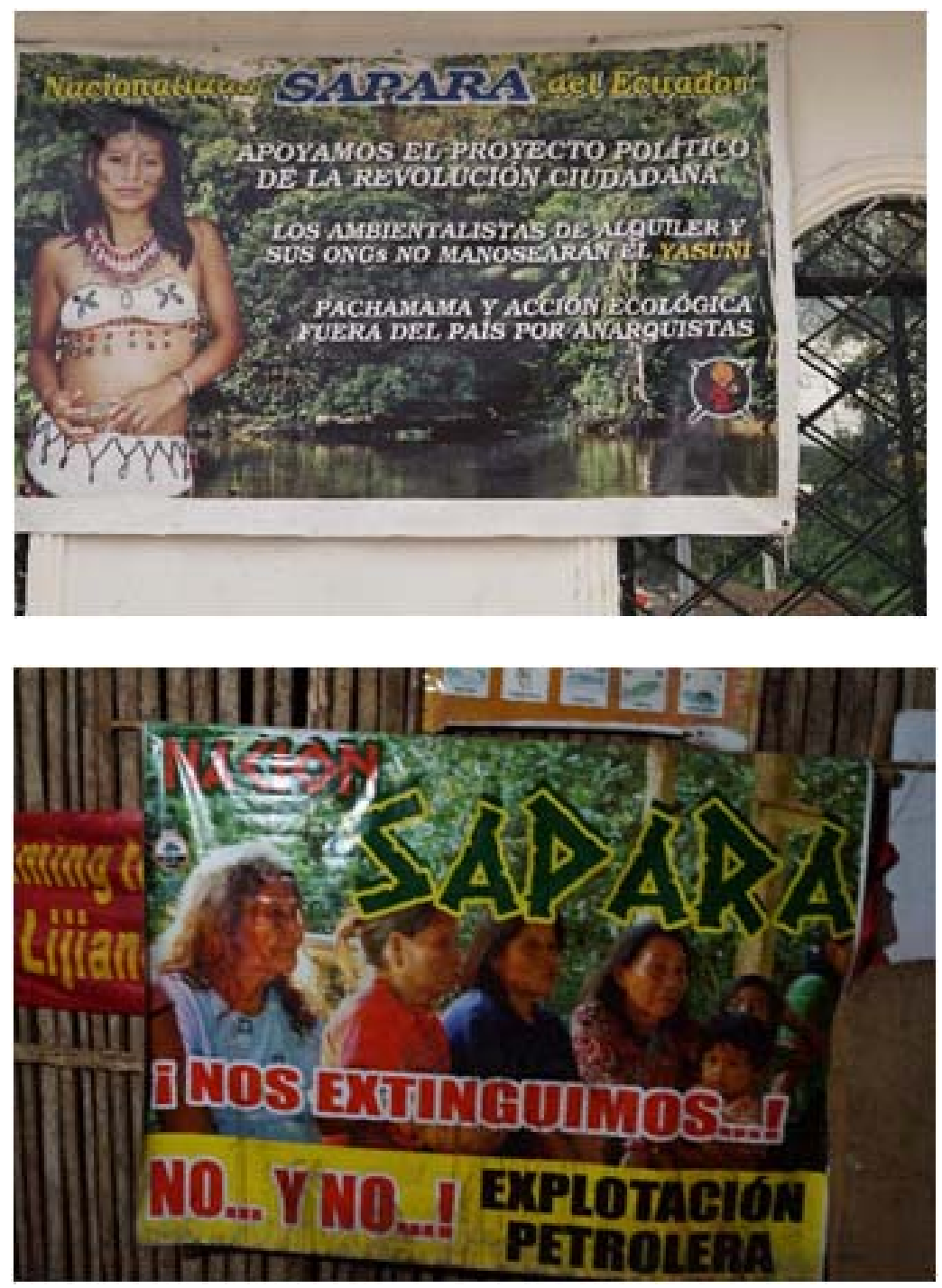

Fotografías de Ivette Vallejo, 2014

La megaminería desató también cooptaciones de dirigentes, fragmentación y debilitamiento de organizaciones como la FICSH (la primera organización amazónica en el país). En varias de ellas se han dado posicionamientos en contra, y otros a favor de la minería. Se limitó también la potencialidad que tenía el Pueblo Shuar Arutam que pudo devenir en Circunscripción Territorial Indígena (CTI), amparado en la Constitución de 2008.

Las repercusiones fueron la desconexión entre dirigencias y bases, surgimiento de facciones y dirigencias paralelas que eran reconocidas desde la Secretaría de Gestión de la Política ${ }^{6}$. En definitiva, se desestabilizaron los procesos organizativos indígenas. Entre las dirigencias indígenas amazónicos se produjeron formas de respaldo y apoyo, así como cuestionamientos reactivos, posicionamientos que no podríamos claramente dividir entre regiones de la Amazonía. Hubo mayor apoyo de las organizaciones indígenas a la política gubernamental neo-extractiva en las provincias del norte amazónico (Sucumbíos, Orellana y Napo), y menor apoyo en el 
centro (en Pastaza) y sur amazónico (Morona Santiago y Zamora). No obstante, también en el centro y suroriente hubo dirigentes que se alinearon a la política gubernamental con distintos intereses: expectativas por el desarrollo e inclusión social, participación de la renta petrolera ${ }^{7}$ y minera, interés por el programa Socio Bosque del Ministerio de Ambiente consistente en incentivos para la conservación. También confluyó la ilusión de configurar Circunscripciones Territoriales Indígenas (CTI) con dotación de presupuestos para implementar Planes de Vida ${ }^{8}$.

Otros factores que pudieron incidir el apoyo al gobierno en la Amazonía norte y centro son cierto fomento a cultivos "promisorios" como el cacao fino de aroma y café. Por ello se podría decir que la etnopolítica amazónica en la relación Estado y pueblos indígenas "ha fluctuado entre alianzas y resistencias" (Vallejo et al., 2017, p. 37) que se han expresado en el voto amazónico en distintos momentos eleccionarios o de consulta popular, el cuestionamiento en marchas a nivel nacional o en la participación en contra-marchas de respaldo.

Algunos dirigentes amazónicos, como A’I Cofan, de Sucumbíos, en el norte amazónico, consideraban que el gobierno tenía propuestas tangibles de desarrollo y que ningún otro había invertido igual en la Amazonía. $\mathrm{Al}$ aproximarse y aliarse con el gobierno de Correa se buscaba romper con la dependencia hacia ONG, asumiendo propias decisiones sobre el desarrollo (Vallejo et al., 2017). ${ }^{9}$ Según dirigentes del norte amazónico, la gestión gubernamental se plasmaba en inversión en educación, vialidad, salud y emprendimientos. En su perspectiva, "los indígenas son tomados en cuenta" y "existía el interés por resarcir a los pueblos amazónicos históricamente olvidados por gobiernos precedentes durante el auge petrolero" (Vallejo et al 2017, 47). La inclusión económica, fue usada por el gobierno como recurso de propaganda desplazando el tema de los derechos étnicos” (Martínez Novo, 2011). Como plantea Colloredo-Mansfeld (2009) las comunidades indígenas con sus organizaciones son heterogéneas y diversas, y en los liderazgos indígenas inciden las aspiraciones de movilidad social.

Al término del largo período de Correa y una vez que la posibilidad de una reelección fue frustrada mediante consulta popular, el decenio de la Revolución Ciudadana pasó a revelar una realidad diferente: déficit fiscal, alto endeudamiento público, y reproducción del régimen de acumulación que se había pretendido superar basado en la ampliación de las fronteras extractivas que había abierto facilidades al capitalismo rentista. El proyecto basado en el Buen Vivir, no se reflejó materialmente, la pobreza persistió a la par que la experiencia de contaminación por poblaciones marginalizadas (Valdivia 2005; Lu et al 2017). Esto, si bien se manejó como una nueva forma de conducir la explotación petrolera y la distribución de su renta (Bebbington 2009), utilizando el tema de la inversión de regalías, en la práctica, en la planeación del Buen Vivir, la plurinacionalidad fue relegada. Los derechos de los pueblos indígenas quedaron bajo la sombra de una “ciudadanía inclusiva” (Guerrero, 2010 en Lu et al., 2017).

\section{Las mujeres amazónicas: ¿actoras emergentes?}

Las mujeres éramos unidas, acompañamos a los hombres. Teníamos una sola voz. Lucharon nuestros abuelos, tíos y tías. Si no hubiéramos hecho eso no tuviéramos tanto territorio. En ese tiempo la colonización se llevaba nuestros territorios. Logramos la legalización de territorios en Pastaza. Hoy en día las mujeres tenemos un papel importante. Algunos compañeros que organizaron la marcha (en alusión a la marcha de 1992) cambiaron de idea y trataron de negociar el territorio. Las mujeres en cambio seguimos luchando y tenemos mentalidad de defender nuestra pachamama, que no se explote (Zoila Castillo Tuti. Taller Género y Participación Política, Puyo. 25 de septiembre, 2018).

A partir de la XI Ronda Petrolera entre el 2013 al 2017, al percatarse de que algunos dirigentes hombres habían firmado convenios con la Secretaría de Hidrocarburos, mujeres shiwiar, kichwa, sapara, waorani y shuar comenzaron a articularse. Se reunieron con mujeres urbanas del Puyo y activistas de la ONG Acción Ecológica. Con el temor del despojo de sus territorios, la contaminación de esteros y ríos, la pérdida de cultivos y el alejamiento de la fauna, apuntalaron con fuerza la resistencia a la expansión de las fronteras extractivas. Se tornaron el sostén de la misma. En talleres y encuentros fueron enunciando mandatos para sus organizaciones y ante el Estado (Vallejo y García, 2017). 
Un Primer Encuentro de Mujeres de las Organizaciones Indígenas Amazónicas por la defensa de la vida, el territorio y el Buen Vivir, se efectuó en Puyo en junio de 2013. Resultó en una Agenda de Mujeres Indígenas frente al extractivismo, con varias líneas de acción. De la Asamblea Mujeres en Vigilia por la Vida realizada en Fátima en octubre de 2013, surgió un manifiesto dirigido al presidente Rafael Correa en el que cuestionaron las concesiones petroleras y las consultas previas reglamentadas por el Decreto 1247. Éstas no se habían efectuado conforme a la normativa internacional establecida en el Convenio 169 de la OIT: los procesos de consulta se efectuaron en tiempos cortos, no tenían pertinencia cultural, no se efectuaron en las distintas lenguas indígenas, no se ajustaron a las formas propias de toma de decisiones, ni habían respetado las estructuras organizativas internas y que principalmente, las voces de las mujeres no habían sido consideradas.

Una Marcha de mujeres en defensa de sus “territorios y derechos” se desplegó desde Puyo a la ciudad de Quito en octubre de 2013. Al llegar a la capital el presidente Correa no les recibió y más bien les exhortó a presenciar la inauguración de la primera ciudad del milenio en Playas de Cuyabeno (Sucumbíos). Una siguiente marcha de mujeres indígenas de la Amazonía centro fue realizada en Puyo en el Día internacional de la mujer8 de marzo de 2016. Así mismo entre 2015 y 2016 mujeres kichwa adoptaron nuevos repertorios de acción como los yakuchaski (recorridos ribereños) por las cuencas de los ríos Bobonaza y Curaray, para alertar y sensibilizar sobre el extractivismo petrolero y a la vez recoger mandatos de las bases. Un yakuchaski se efectúo también en territorio shiwiar, acompañadas de activistas de Acción Ecológica. En estas visitas ribereñas, en cada comunidad se entregaron varas de mando a mujeres comprometidas con la defensa del territorio. Es así como fueron denominándose “Defensoras de la selva”.

Figura 4 y 5.

\section{Recorridos ribereños (YakuChaski)}
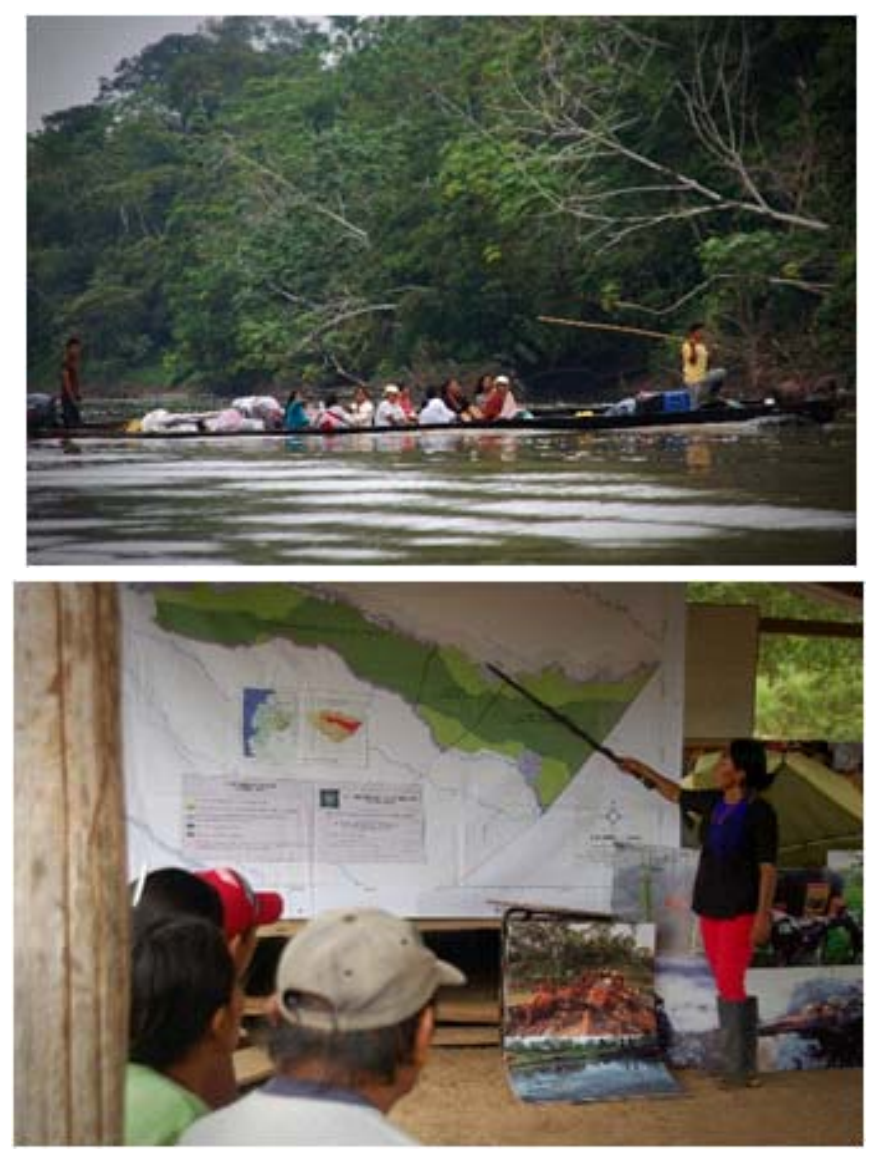

Fotografía de Miriam García Torres 
Los posicionamientos de lideresas mujeres al interior de las organizaciones, e incluso en la CONFENIAE no tuvieron suficiente respaldo de dirigentes hombres. Por parte del Estado, fueron objeto de intimidación. Ante ello, a nivel internacional, ante la CIDH y en el Foro Permanente para Cuestiones Indígenas lideresas waorani, sapara y kichwa posicionaron sus voces demandando al Estado por amedrentamiento, violencia y judicialización de la resistencia.

En el 2018, con un nuevo gobierno del movimiento Alianza País, presidido por Lenin Moreno que a pocos meses se distanció de su predecesor, no obstante, las políticas extractivas petroleras y mineras se mantuvieron. En la nueva coyuntura una marcha de alrededor de 300 mujeres indígenas de las distintas regiones de la Amazonía (norte, centro y sur), marchó hasta llegar a la capital el 12 de marzo. Fueron recibidas por el secretario de la presidencia, y para tener una audiencia con el presidente, se les instó a retornar el 22 de marzo. En la casa de presidencial, presentaron un mandato relativo a su visión sobre la problemática minera y petrolera que afecta a los territorios y pueblos amazónicos.

El denominado "Mandato de las Mujeres Amazónicas Defensoras de la Selva de las bases frente al Extractivismo” incluyó 22 puntos y, entre sus aspectos centrales, demandó: la anulación de los contratos y/o convenios y concesiones otorgadas a las empresas mineras y petroleras en el centro sur de la Amazonía; que los territorios y pueblos indígenas sean declarados libres de actividades extractivas como el petróleo, la minería y madera; la nulidad de las concesiones petroleras (de la XI Ronda)-bloques 79,83, 74,75 y 28; anulación de concesiones mineras en territorio shuar y campesino en Morona Santiago y Zamora Chinchipe al sur oriente.

Con respecto a la Amazonía norte con alrededor de cinco décadas de actividades extractivas y el bloque 10 en la Amazonía centro con explotación desde fines de la década del ochenta, el Mandato incluía cuestiones como la reparación integral ambiental y social de las afectaciones de la extracción petrolera, el reconocimiento y pago de la deuda ecológica, e indemnización por daños a las nacionalidades siekopai, cofan, siona, kichwa y waorani. En el mandato de las mujeres se enuncian problemáticas de género relacionadas con las dinámicas patriarcales que se incrustan en sus territorios restringiendo su libre movilidad generando acoso y violencia física, psicológica y sexual. Enuncian las mujeres que el incremento de la violencia de género en sus comunidades, pueblos y estructuras organizativas está asociado al extractivismo petrolero en la Amazonía norte y Villano en Pastaza, en la Amazonía centro. Situaciones similares les preocupa a mujeres shuar de la Codillera del Cóndor en la Amazonía sur, quienes han experimentado despojo y vulneración de su derecho al territorio.

Las mujeres Amazónicas en su mandato se adelantaron a lo que se preveía aproximarse, la convocatoria por parte del Ministerio de Recursos Naturales no Renovables a una nueva ronda de licitación de bloques petroleros (sobre territorio andoa, shuar, kichwa, shiwiar, waoysapara). El 23 de octubre de 2018 el ministro de Hidrocarburos anunció que de 16 bloques que se tenía como objetivo licitar, se lanzaría la convocatoria de los bloques 86 y 87 y que se llegará a acuerdos con Petro Perúpara conducir el petróleo por el oleoducto norperuano. Aseguró que no habría afectaciones a comunidades, al no estar situadas en las áreas. Esto generó la indignación de mujeres lideresas, quienes se apostaron en las oficinas de PetroEcuador y realizaron una vigilia para resaltar que no se trata de territorios vacíos, que son territorios vivos, donde habitan pueblos indígenas.

Las denominadas Defensoras de la selva, se reúnen, organizan congresos, efectúan marchas hacia la capital evidenciando una activa agencia política. Reiteran que no es de ahora su lucha, ésta tiene una continuidad histórica. Estuvieron presentes en marchas históricas de los noventa por la titulación y defensa de territorios, y frente a otros intentos de rondas petroleras en gobiernos neoliberales. Lo distinto entonces es que desde el decenio previo han impulsado una vocería propia y con su protagonismo han mantenido la resistencia en sus territorios, evitando así la irrupción del Estado y transnacionales. Esto, en coyunturas en que las dirigencias masculinas no se han ajustado a las decisiones asamblearias, o se han alineado a actores gubernamentales.

En el caso del pueblo kichwadekawsak sacha, Nancy Santi, una dirigente de la Asociación de Mujeres ha llegado a ocupar el cargo de kuraka, y ha sido pilar en restablecer la unidad de las comunidades y de que las comunidades lleguen a consensuar el no permitir actividades extractivas en su territorio. Actualmente mujeres lideresas en conjunto con dirigentes de organizaciones shiwiar, shuar y achuar y de la CONFENIAE efectúan 
itinerarios ante instancias gubernamentales para enunciar su rechazo a la ampliación de las fronteras extractivas, consolidando así los procesos organizativos en la Amazonía, y superar los quiebres y la fragmentación. Las mujeres dejan claro que su lucha no es exclusivamente para sí mismas, sino para sus pueblos y para el mantenimiento de las relaciones de vida, que tienen con otros seres y entidades en sus territorios.

Figura 6.

Mujeres Defensoras de la Selva

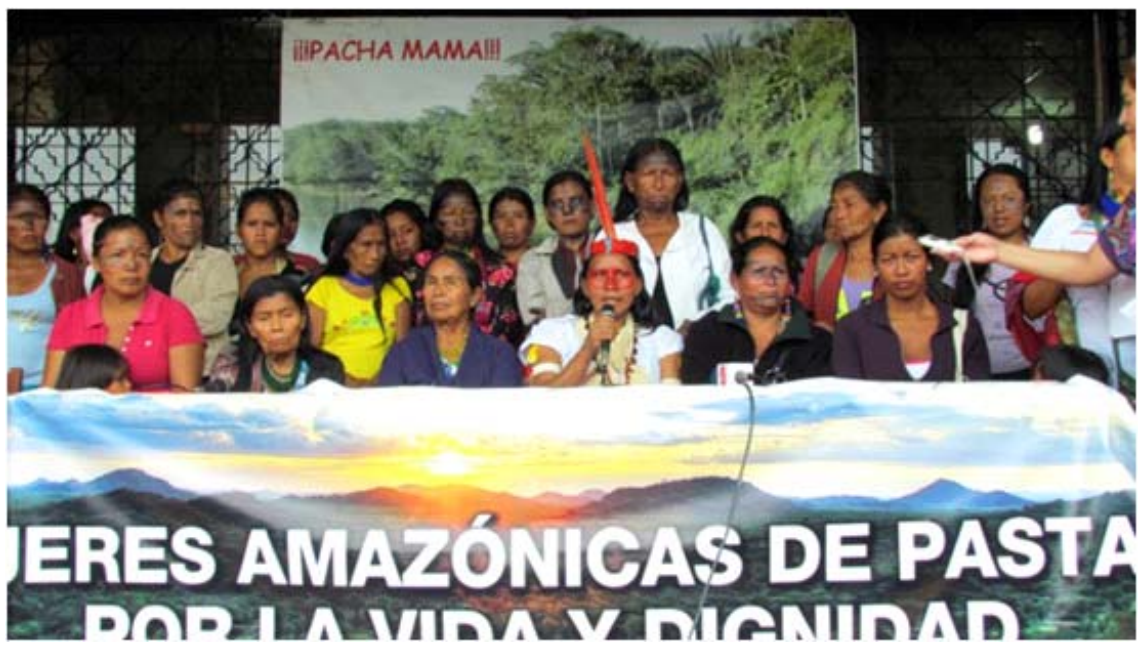

Fuente:https://www.salvalaselva.org/noticias/5474/mujeres-amazonicas-defienden-la-selva-para-la-vida

El que las mujeres se erijan frente al extractivismo minero y petrolero puede explicarse a partir de la especial relación que tienen con su territorio y con la naturaleza. La ampliación de las fronteras extractivas les genera afectación directa a sus medios de vida con la disminución de la productividad de las chacras, esfera de trabajo del que las mujeres son responsables. Ellas han estado más ligadas a lo que Schmink y Wood (1987) denominan sistemas económicos de reproducción simple, mientras que los hombres se tienden a articular con mayor fluidez, aunque en condición de subalternidad, a las economías extractivas y a relaciones asalariadas que no son estables (Knauft, 1997; Rubenstein, 2004). Las mujeres cuestionan la profundización de las asimetrías de género que ocurre en las comunidades, a partir de la influencia de las industrias extractivas que privilegian la movilidad y el trabajo masculino en las economíasregionales (Viatori, 2008).

El despojo de los territorios tiene efectos en la vida de las mujeres (Yepez y Teijilingen, 2017). Ellas evidencian que se crean mayores desigualdades y vulnerabilidades, incluidas las de género, en los contextos extractivos, y que a la par del despojo de territorios que ocurre con la ampliación de las fronteras extractivas, se masculiniza la interacción en los territorios, para abrir paso al petróleo y la minería a gran escala. Con la inserción de empresas extractivas, por lo general actores externos se insertan en sus territorios, ocurriendo acoso por la llegada de mano de obra masculina, y produciendo incertidumbre en la cotidianidad (Yépez y Van Teijlinger 2017). Los trabajos de cuidado que incluyen la producción en las chakras para la subsistencia familiar son desvalorizados, al implantarse con mayor importancia el trabajo pagado masculino. Los hombres dejan sus responsabilidades en la apertura de agroecosistemas, en el aprovisionamiento mediante caza y pesca, así como la participación en mingas, lo que trae como consecuencia que el sostenimiento familiar y comunitario recaiga en las mujeres, repercutiendo en una mayor carga de trabajo.

Sin escindirse de las organizaciones indígenas, las mujeres están dinamizando la etnopolítica amazónica. Si anteriormente, la vocería e interlocución con actores externos (instituciones del Estado, iglesias, ONG y otros) la tenían de forma exclusiva los dirigentes hombres, en la actualidad las mujeres asumen posicionamientos fuera de formatos ventrílocuos. 
Hay que considerar que este protagonismo si bien autónomo, también es acompañado y se va perfilando en diálogo y acompañamiento con activistas de ONG ecologistas y otras que buscan apuntalar sostenibilidad económica y una mayor autonomía indígena en los territorios. Enunciados esencializantes de los pueblos indígenas como protectores y guardianes de bosques de los tiempos iniciales de alianzas entre movimientos étnicos y ecologistas de fines de los noventa, se han movido hacia las mujeres indígenas. En ejercicios de auto-esencialización estratégica, se ubican ante el Estado y otros actores como “defensoras de la selva”.

Lo que ocurre en la Amazonía tiene coincidencia con otros procesos de las mujeres indígenas en países de América Latina. Si bien los sistemas de gobernanza basados en la comunidad de los pueblos indígenas tienden a enfatizar la participación, deliberación y servicios en términos de lo colectivo, suelen discriminar a las mujeres indígenas. Las exclusiones de raza, etnicidad, clase y género intersectadas les han excluido de los sistemas de gobernanza comunitarios. Frente a esto ellas han seguido diferentes estrategias para buscar transformaciones en sus organizaciones y costumbres y han planteado nuevas formas de imaginar lo plural y la ciudadanía de forma menos patriarcal (Sieder y Barrera, 2017). Desafían las formas de exclusión para transformar las organizaciones e identidades colectivas de los movimientos indígenas, el género y la etnicidad. Han logrado insertar demandas específicas, sea creando espacios autónomos al interior de organizaciones mixtas, estableciendo organizaciones independientes, o manteniendo un paralelismo organizativo, en que se mantienen afiliadas a organizaciones mixtas. En cierta medida, la debilidad del movimiento indígena en recientes años proporcionó mayor espacio para que las mujeres se ubiquen como actoras públicas y se tornen representantes legítimas frente a Estado y sociedad civil (Rousseau y Morales, 2016).

\section{Conclusiones}

En el artículo se ha plasmado el argumento de que en el decenio 2007-2017 el gobierno de Alianza País reforzó el extractivismo petrolero e inauguró la minería a gran escala utilizando prácticas de gobiernos de otrora para dividir y cooptar dirigencias. El uso de una retórica relacionada con la distribución rentista de regalías para la construcción de una nueva Amazonía generó polarización entre los pueblos y nacionalidades.

En medio de la profundización extractiva, las organizaciones indígenas politizaron su agencialidad, en unos casos como se ha descrito en apoyo a la política de desarrollo marcada por el extractivismo y la distribución rentista ofrecida, y, en otros casos, principalmente en el centro y suramazónico, en oposición y defensa de territorios, cultura y medios de vida.

Dentro de los posicionamientos de resistencia y contestación, las mujeres indígenas amazónicas se han perfilado con un alto protagonismo en alianza con el activismo ecológico ecofeminista, que ha llevado a que la etnopolítica ecologizada de la última década pase de las luchas por el reconocimiento de etnicidades y territorios étnicos, a la reparación ambiental y social, y a la prevención de nuevas formas de despojo.

En la marcha más reciente de marzo de 2018, las articulaciones de mujeres indígenas que años antes se habían concentrado en Pastaza, en la Amazonía centro, irradiaron a mujeres del norte y sur amazónico, abriendo nuevas proyecciones etnopolíticas y ecopolíticas feminizadas más amplias. Laslideresas amazónicas indican que sus luchas contemporáneas dan continuidad a luchas previas en que han estado presentes en defensa de sus territorios. No obstante, ahora su papel es con una vocería propia, liberada de ventriloquismos. Están conscientes no obstante que su participación tiene limitantes, en la misma estructura del andamiaje organizativo de sus comunidades, pueblos y nacionalidades indígenas, y en las estructuras patriarcales del Estado. Refieren que se requieren procesos organizativos de mujeres desde las bases, sostenidos en agendas que visualicen sus necesidades y demandas específicas, así como refuercen aquellas de las organizaciones de sus pueblos con planteamientos relacionados con la democratización de las decisiones ambientales que pesan sobre sus territorios, las políticas del desarrollo, y cuestiones como la reparación integral por afectaciones ambientales. 


\title{
Notas
}

\begin{abstract}
${ }^{1}$ Los modos tradicionales de ejercicio político indígena según la literatura etnográfica amazónica no están basados en la estratificación social, ni en sistemas políticos jerarquizados; sino en saberes generadores que implican la fuerza de la palabra, el carisma y la fuerza guerrera. Entre los indígenas el liderazgo dependiente del prestigio, no es jerárquico (Clastres, 1980; Kracke y Thomas D.J, 1982; Overing, 1975 en Correa F., 2017). Las formas de poder, están relacionados con atributos de control simbólico sobre ciertos recursos para actuar en la sobrenaturaleza por medios mágicos; es decir para el control sobre los medios místicos de reproducción que aseguran procesos productivos y reproductivos de la sociedad (Descola, 1988; Santos Granero, 1986 en Correa F., 2017).
\end{abstract}

${ }^{2}$ Por ejemplo, la Federación Achuar del Ecuador, adoptó el nombre de NAE, como Nacionalidad Achuar del Ecuador; la ONHAE pasó a denominarse Nacionalidad Waorani del Ecuador (NAWE) y así otras también.

${ }^{3}$ La ley minera de 2009 (art 23), cambió el contenido del derecho a la consulta previa, al estipular que "el proceso de consulta tendrá por objeto promover el desarrollo sustentable de la actividad minera” (Art 87 Ley Minera 2009), limitando cualquier oposición. Prioriza la ley, el derecho a la prospección minera, sobre el derecho al territorio (Art 28); inclusive establece que el ejecutivo puede peticionar a la Asamblea Nacional para concesionar en Áreas Protegidas. En el 2013, la Ley Orgánica Reformatorio a la Ley de Mineríaa del 2009 suavizó requisitos antes fijados y lo que establece la Constitución, y como resultado no se llegaron a aplicar procesos de consulta previa en comunidades amazónicas.

${ }^{4}$ Casos perturbadores son aquellos como en septiembre de 2015, cuando se produjo el desalojo forzoso de familias campesinas por miembros de seguridad de la empresa acompañados por fuerza pública en el barrio de Tundayme (Proyecto Mirador); 135 efectivos custodiaban los intereses del consorcio chino. También el caso del desalojo de la comunidad shuar de Nankintz en agosto de 2016; la irrupción militarizada cuando shuar deciden retornar a la comunidad, seguida del asedio y persecución de dirigentes y miembros de las familias, lo que generó que estas se resguarden en el bosque o busquen ser recibidas por familiares en comunidades vecinas.

${ }^{5}$ En septiembre de 2015 se aprovechó de un manejo irregular del fondo semilla de la organización obtenido por Convenio con el Programa Sociobos que con el Ministerio de Ambiente, para quitar la personería jurídica a la dirigencia de NASHIE, y el gobierno registró el nombramiento de una nueva dirigencia electa autoconvocada en agosto de 2015, afín al movimiento Alianza País. En el caso de la NAE con la llegada a presidencia de Rubén Tsamaren en 2014 las bases cuestionaron que no tenga una posición firme frente al extractivismo y que mantuviera una actitud dialogante con el Estado. Fue depuesto en septiembre de 2015, pero después la Secretaría Nacional de Gestión de la política no registró la nueva dirigencia e intentó crear un segundo consejo de gobierno resposicionándolo (Vallejo et al., 2017). Similares intromisiones hubo en CONFENIAE que se dividió entre dos facciones.

${ }^{6}$ Varias organizaciones como la achuar NAE, shiwiar NASHIE, y ASIA - kichwa- de Arajuno tuvieron dificultades en obtener el nombramiento de dirigencias por parte de la Secretaría de Gestión de la Política. En otros casos facciones alineadas al gobierno conseguían rápidamente su nombramiento.

${ }^{7}$ En los procesos de consulta previa de la XI Ronda, que más que nada fueron socializaciones, dirigentes de la Nacionalidad Sapara (NASE), la dirigencia de ACIA en Arajuno, de la comuna San Jacinto del Pindo, de la Nacionalidad Andwa, la dirigencia kichwa de PAKIC y de la comuna Canelos llegaron a firmar convenios permitiendo actividades extractivas en sus territorios. Dirigencias masculinas de la Coordinación Kichwa tuvieron una actitud de respaldo al gobierno en su política neo-extractiva, si bien algunas bases organizativas tenían un posicionamiento anti extractivo.

${ }^{8}$ En la mirada de algunos dirigentes históricos, las CTI podían posibilidad alcanzar el sueño de ir más allá de la titulación de territorios y de avanzar en constituir jurisdicciones territoriales administrativas que cuenten con presupuesto del Estado.

${ }^{9}$ Estas posiciones fueron enfáticas en dirigentes jóvenes del pueblo A’I Cofán, de Dureno que accedieron mediante negociaciones con el gobierno a la construcción de una de las tres ciudades del Milenio en Sucumbíos.

\section{Bibliografía}

Bayón, M. y Wilson, J. (2017). La selva de los elefantes blancos. Megaproyectos y extractivismos en la Amazonía ecuatoriana. Quito, Ecuador: AbyaYala, IEETM.

Becker, M. (2013). Ecuador: Indigenous Struggles and the Ambiguities of Electoral Power. En Webber, J. y Carr B.The New Latin American Left: cracks in the Empire.New York, US: Rowman /LittlefieldPublishers Inc. (pp.213-232).

Biersack, A. (2006). Reimagining Political Ecology.Durham\&London: Duke University Press.

Breton, V. (2005). Capital social y etnodesarrollo en los Andes. Quito, Ecuador: CAAP 
Dávalos, P. y Albuja, V. (2014). Ecuador: Extractivist Dynamics, Politics and Discourse. En Veltmeyer y Petras James (eds).The New Extractivism: A Post-Neoliberal Development Model of Imperialism of the TwentyFirst Century(pp144-171).London, UK: Zed.

Guerrero, F. y Ospina, P. (2003). El poder de la comunidad. Ajuste estructural y movimiento indígena en los Andes ecuatorianos. Quito, Ecuador: CLACSO.

Hale, C. (2002). Does multiculturalism menace? Gobernance, cultural rights, and the politics of identity in Guatemala.Journal of Latin American Stuides, (pp. 485-524).

Lu, F.,Valdivia, G. y Silva, N. (2017).Oil, revolution, and indigenous citizenship in Ecuadorian Amazonia. New York, US:Palgrave macmillan

Knauft, B. (1997). Gender Identity, Political Economy and Modernity in Melanesia and Amazonia.Journal of the Royal Anthropological Institute 3(2) 233-259.

Martínez Novo, C.(2013). Why are indigenous organizations declining in Latin America?.En Caulkins, D. y Jordan A.A companion to organizational Anthropology,(pp.471-492)West Sussex, US: Wiley-Blackwell.

(2011). Etnodesarrollo en la Revolución Ciudadana en Ecuador: Avances, ambigüedades y retrocesos. En Palenzuela P y Olivi, A (coords). Etnicidad y desarrollo en los Andes. Sevilla, España: Universidad de Sevilla.

Martínez Sastre, J. (2011). El salvaje ecológico: identidad, ambientalismo y territorio en la Cuenca Baja del Río Curaray (Amazonía ecuatoriana). En Palenzuela, P. y Olivi, A. (coords). Etnicidad y desarrollo en los Andes. Sevilla, España: Universidad de Sevilla.

Ospina, P. (2015). Crisis y tendencias económicas en el Ecuador de Rafael Correa; informe de coyuntura, abril de 2015. Línea de Fuego 28/04/2015.

Muratorio, B. (1998). Indigenous women's identities and the politics of cultural reproduction in the Ecuadorian Amazon,American Anthropologist 100(2), 409-420.

Postero, N y Zamosc, L (2004). The struggle for Indigenous Rights in Latin America. Brighton, UK: Sussex Academic Press.

Rappaport, J. (2005). Intercultural Utopias: Public Intellectuals, Cultural experimentation an Ethnic Pluralism in Colombia. Durham, NC: Duke University Press.

Rocheleau, B., Thomas-Slayter y E. Wangari (1996).Gender and Environment: A feminist Political Ecology Perspective. In Feminist Political Ecology: Global Issues and Local Experiences, (pp.3-23) .London, UK: Routledge,

Rousseau, S.yMorales, A. (2016).Paths towards Autonomy in Indigenous Women’s Movements: Mexico, Peru, Bolivia.Journal of Latin American Studies, 48 (1), 33-60.

Rénique, G. (2009). Law of the Jungle in Peru: Indigenous Amazonian Uprising against Neoliberalism. Socialism and Democracy(24), 117-35.

Sieder, R. y Barrera, A. (2017).Women and Legal Pluralism: Lessons from Indigenous Governance Systems in the Andes. Journal of LatinAmericaStudies. 49 (3), 633-658.

Vallejo, I. (2003). Políticas étnicas y ciudadanía: trayectorias comparativas de las organizaciones indígenas amazónicas en Ecuador y Brasil. En Revista Anthropológicas, 14 (1 e 2), 185-212. 
Vallejo, I. y García-Torres, M. (2017). Mujeres indígenas y neo-extractivismo petrolero en la Amazonía centro del Ecuador: Reflexiones sobre ecologías y ontologías políticas en articulación. RevistaBrújula, 11.

Vann Cott, D.L. (2009). Indigenous movements lose momentum. Current History, 108 (715), 83-89.

Viatori, M. (2008) Gender and indigenous self-representation in the Sapara Nationality of Ecuador.Latin American and Caribbean Ethnic Studies 3(2), 193-203.

Yashar, D (2005). Contesting Citizenship in Latin America: The Rise of Indigenous Movements and the PostLiberal Challenge. Cambridge, UK: Cambridge University Press.

Zamosc, L (2007). The Indian movement and political democracy in Ecuador.Latin American Politics and Society. 49 (3) $1-34$ 